Fr microcatheter was used to selectively catheterize the distal frontal and posterior branches of the MMA. A 5-Fr intermediate catheter was advanced proximal to the origin of the MMA in the internal maxillary artery and used for Dextrose 5\% (Sugar- Rush) injection via a $60 \mathrm{ml}$ syringe while the primary operator was injecting n-BCA through the microcatheter. Complete obliteration of frontal and posterior branch of the MMA and lack of SDH recurrence in 3-6 months follow up CT scan were defined as efficacy outcomes. Cranial nerve palsy, vision loss, transient neurologic deficit and stroke were defined as safety outcomes.

Results A total of 61 patients were identified with a mean $( \pm S D)$ age of $62.5 \pm 9$. Seventy eight percent of the patients were male. Median (IQR) NIHSS score was 1 (3), 67\% of the patients had midline shift and $36 \%$ had bilateral SDH. Forty nine percent of the patients had craniotomy, burr hole or Subdural Evacuating Port System (SEPS) placement prior to embolization. The embolization was performed under MAC anesthesia in $39(64 \%)$ patients and radial access in $29(48 \%)$ patients. In 6 patients (10\%), coil embolization of the origin of the frontal or posterior branch was performed as superselective catheterization of the branch was unsuccessful due to tortuous anatomy. Complete obliteration of frontal and posterior branches was achieved in $100 \%$ of the cases. In $25 \%$ of the patients, n-BCA penetrated the contralateral side. Follow up CT scan at 3-months and 6- months were available in $91 \%$ of the patients. Recurrent $\mathrm{SDH}$ was seen in only 1 patient on the side contralateral to treatment. No incidence of cranial nerve palsy, vision loss, or stroke occurred. One patient suffered a transient neurological deficit.

Conclusion MMA embolization using diluted n-BCA with concomitant Dextrose 5\% injection (Sugar-Rush) is associated with a high degree of distal penetration and complete branch occlusion and minimal risk of cranial nerve palsy or other thrombo-embolic complications. Clinical trials are warranted to compare long-term efficacy of this procedure with standard of care management.

Disclosures S. Majidi: None. S. Matsoukas: None. R. De Leacy: None. P. Morgenstern: None. R. Soni: None. H. Shoirah: None. T. Shigematsu: None. J. Bederson: None. A. Berenstein: None. J. Mocco: None. J. Fifi: None. C. Kellner: None.

\section{0-031 30-DAY EMERGENCY DEPARTMENT UTILIZATION FOR CHRONIC SUBDURAL HEMATOMAS FOLLOWING SURGICAL EVACUATION WITH AND WITHOUT MIDDLE MENINGEAL ARTERY EMBOLIZATION}

J Catapano*, C Nguyen, V Srinivasan, C Rutledge, T Cole, J Baranoski, S Elmasry, M Lawton, A Jadhav, A Ducruet, F Albuquerque. Neurosurgery, BNI, Phoenix, AZ

10.1136/neurintsurg-2021-SNIS.31

Background Middle meningeal artery (MMA) embolization for chronic subdural hematomas (cSDHs) has been found to be associated with fewer treatment failures compared to surgical evacuation. The present study compares 30-day emergency department (ED) utilization for patients with cSDHs with and without adjunctive MMA embolization.

Methods All patients who presented with a cSDH to a quaternary center from January 1st, 2018 to December 31, 2020 were retrospectively reviewed. Patients were separated into two cohorts: surgery alone and combined surgery with MMA embolization. The surgery only cohort comprised of patients who presented during the first two years of the cohort. The combined surgery and MMA embolization cohort comprised of all patients with a combined treatment during the entire three-year study period. Patients in the combined cohort comprised of planned combined therapies, as well as patients who failed surgery and required MMA embolization. Primary outcome compared was 30-day ED presentation and readmission. Patients with bilateral treatment were analyzed for admission cSDH size.

Results Of the 137 patients who met the study criteria, 28 patients (20\%) had combined MMA embolization and surgery. In the 28 combined patients, 15 (54\%) were planned MMA embolization and 13 (46\%) were due to surgical failure. There was no difference between the two cohorts in mean age, gender, admission Glasgow Coma Score (GCS), discharge GCS, comorbidities, or previous trauma. The mean $\mathrm{cSDH}$ size on presentation in the surgery alone cohort $(\mathrm{N}=123,20.5 \mathrm{~mm}$, $\mathrm{sD}$ 6.9) was comparable to the combined group $(\mathrm{N}=32$, $18.7 \mathrm{~mm}, \mathrm{sD} 4.5)(\mathrm{p}=0.16)$. A significant higher percentage of patients in the surgery alone $(\mathrm{N}=32,29 \%)$ cohort presented within 30-days to the ED compared to combined MMA embolization with surgery $(\mathrm{N}=2,7 \%)(\mathrm{p}=0.02)$. There was no significant difference in readmission rates between the surgery alone $(\mathrm{N}=16,15 \%$,$) and combined cohort (\mathrm{N}=1,4 \%)$ $(p=0.11)$. Nine patients $(8 \%)$ in the surgery alone cohort were readmitted due to significant reaccumulation/residual compared to only one patient $(4 \%)$ in the combined group $(p=0.4)$.

Abstract 0-031 Table 1 Demographics and characteristics of chronic subdural hematoma patients with surgery versus combined MMA embolization and surgery

\begin{tabular}{llll}
\hline \multicolumn{1}{c}{ Characteristic } & $\begin{array}{c}\text { MMA } \\
\text { Embolization } \\
(\mathbf{N = 2 8 )}\end{array}$ & Surgery (N=109) & \multicolumn{1}{c}{ p Value } \\
\hline Age (yr), mean (SD) & $71(10.2)$ & $70(12.8)$ & 0.86 \\
Male sex & $21(75)$ & $81(74)$ & 0.94 \\
GCS Presentation & $14(2.6)$ & $14(2.2)$ & 0.77 \\
GCS Discharge & $14(2.3)$ & $14(2.1)$ & 0.70 \\
Comorbid condition & & & \\
Hypertension & $16(57)$ & $54(50)$ & 0.47 \\
Diabetes & $8(29)$ & $27(25)$ & 0.68 \\
CAD & $12(43)$ & $36(33)$ & 0.33 \\
Liver disease & $1(4)$ & $3(3)$ & 0.82 \\
Alcohol abuse & $1(4)$ & $14(13)$ & 0.16 \\
CVA & $2(7)$ & $10(9)$ & 0.73 \\
Coagulopathy & $3(11)$ & $4(4)$ & 0.13 \\
Previous trauma & $17(61)$ & $78(72)$ & 0.27 \\
\hline
\end{tabular}

Abstract 0-031 Table 2 30-Day emergency department presentations and readmissions for chronic subdural hematoma patients with surgery versus combined MMA embolization and surgery

\begin{tabular}{llll}
\hline \multicolumn{1}{c}{ MMA } & & \\
\multicolumn{1}{c}{ Characteristic } & $\begin{array}{c}\text { Embolization } \\
\mathbf{( N = 2 8 )}\end{array}$ & Surgery (N=109) & p Value \\
\hline ED Presentations & $2(7)$ & $32(29)$ & 0.02 \\
Readmissions & $1(4)$ & $16(15)$ & 0.11 \\
\hline
\end{tabular}


Conclusion Combined MMA embolization and surgical evacuation in cSDH patients appears to be associated with decrease 30-day ED utilization compared to surgery alone.

Disclosures J. Catapano: None. C. Nguyen: None. V. Srinivasan: None. C. Rutledge: None. T. Cole: None. J. Baranoski: None. S. Elmasry: None. M. Lawton: None. A. Jadhav: None. A. Ducruet: None. F. Albuquerque: None.

\section{0-032 TREATMENT OUTCOMES FOR ARUBA ELIGIBLE BRAIN ARTERIOVENOUS MALFORMATIONS: A COMPARISON OF REAL WORLD DATA FROM THE NVQI-QOD AVM REGISTRY TO THE ARUBA TRIAL}

${ }^{1} \mathrm{~N}$ Moore ${ }^{*},{ }^{2} \mathrm{R}$ Abdalla, ${ }^{3} \mathrm{~T}$ Patterson, ${ }^{2} \mathrm{Y}$ Moazeni, ${ }^{1} \mathrm{P}$ Rasmussen, ${ }^{1} \mathrm{G}$ Toth, ${ }^{1} \mathrm{M}$ Bain, ${ }^{2} S$ Ansari, 's Hussain. 'Cerebrovascular Neurosurgery, Cleveland Clinic Foundation, Cleveland, $\mathrm{OH} ;{ }^{2}$ Endovascular Neuroradiology, Northwestern University, Chicago, IL; ${ }^{3}$ Cerebrovascular Center, Cleveland Clinic Foundation, Cleveland, $\mathrm{OH}$

\subsection{6/neurintsurg-2021-SNIS.32}

Introduction Since the publication of the ARUBA trial, interventional management of cerebral arteriovenous malformations has become an area of debate. Treatment practices may have changed based on data from this recent trial which suggested that the risk of AVM treatment is greater than medical management in unruptured AVMs. To assess the 'real world' experience with interventional AVM outcomes, we compared outcomes of ARUBA eligible patients from the NVQI-QOD registry database to the ARUBA trial results.

Methods In an IRB approved study, the NVQI-QOD AVM registry database was queried for treated patients between 2017 to present with the following inclusion criteria: age > 18 years, baseline mRS $>1$, unruptured AVMs. 174/364 patients were ARUBA eligible and were included in the analysis. Patients were divided into embolization alone, microsurgery with or without embolization, and gamma knife radiation therapy with or without embolization. Primary outcomes of ischemic/hemorrhagic stroke or death were analyzed with a mean follow up time of 5.8 months (range 1 to 128 months). Results A total of $14(8.0 \%)$ of patients that underwent any type of intervention suffered stroke or mortality. The risk of stroke or death was $6.8 \%$ (5 of 74) for microsurgery, $5.4 \%$ ( 2 of 37 ) for gamma knife, and 10.9\% (7 of 64) for embolization alone. Annual stroke or death rates for all treatments were $7.5 \%$ (13 of 174 ) at one year and $0.57 \%$ (1 of 174) at 2 years.

Conclusion ARUBA eligible patients from the NVQI-QOD registry demonstrate a significantly lower risk of stroke or death with intervention of $8.0 \%(\mathrm{~N}=174)$ compared to the $30.7 \%(\mathrm{~N}=114)$ ARUBA trial interventional risk, and is nearly equivalent to the ARUBA trial medical management risk of 10.1\% ( $\mathrm{N}=109)$ over 33 months.

Disclosures N. Moore: 1; C; SNIS Joe Niekro Research Grant. R. Abdalla: None. T. Patterson: None. Y. Moazeni: None. P. Rasmussen: 2; C; Blockade Medical, Covidien/Medtronic, Stryker Neurovascular, Perflow Medical. 4; C; Perflow Medical. G. Toth: None. M. Bain: 2; C; Stryker Neurovascular. S. Ansari: None. S. Hussain: 2; C; Pulsar Inc.

\section{0-033 INTRACRANIAL VCAM1 AT TIME OF MECHANICAL THROMBECTOMY PREDICTS ISCHEMIC STROKE SEVERITY}

${ }^{1} \mathrm{~B}$ Maglinger*, 'M Sands, 'f Frank, ${ }^{2} \mathrm{C}$ McLouth, ${ }^{3} \mathrm{~A}$ Trout, ${ }^{4} \mathrm{~J}$ Roberts, ${ }^{5} \mathrm{~S}$ Grupke, ${ }^{3} \mathrm{~J}$ Turchan-Cholewo, ${ }^{6} \mathrm{~A}$ Stowe, ${ }^{7} \mathrm{~J}$ Fraser, ${ }^{6} \mathrm{~K}$ Pennypacker. ${ }^{1}$ Department of Neurology, University of Kentucky, Lexington, $K Y_{;}{ }^{2}$ Department of Behavioral Science, University of Kentucky, Lexington, KY; ${ }^{3}$ Department of Neurology; Center for Advanced Translational Stroke Science, University of Kentucky, Lexington, KY; ${ }^{4}$ Department of Neurosurgery, Neuroscience, Center for Advanced Translational Stroke Science, University of Kentucky, Lexington, $K Y ;{ }^{5}$ Department of Neurosurgery and Neuroendovascular Surgery, Covenant Medical Center, Lubbock, TX; ${ }^{6}$ Department of Neurology, Neuroscience, Center for Advanced Translational Stroke Science, University of Kentucky, Lexington, $K Y_{i}$ ${ }^{7}$ Department of Neurology, Neurosurgery, Radiology, Neuroscience, University of Kentucky, Lexington, $K Y$

\subsection{6/neurintsurg-2021-SNIS.33}

Background Emergent Large Vessel Occlusion (ELVO) strokes are devastating ischemic vascular events for which novel treatment options are needed. Using Vascular Cell Adhesion Molecule 1 (VCAM1) as a prototype, the objective of this study was to identify proteomic biomarkers and network signaling functions that are potential therapeutic targets for adjuvant treatment for mechanical thrombectomy.

Methods The Blood And Clot Thrombectomy And Collaboration (BACTRAC) study is a continually enrolling tissue bank and registry from stroke patients undergoing mechanical thrombectomy. Plasma proteins from intracranial (distal to clot) and systemic arterial blood (carotid) from $\mathrm{N}=42$ subjects were analyzed by Olink Proteomics. Statistical analysis of plasma proteomics used independent sample t-tests, correlations, linear regression, and robust regression models to determine network signaling and predictors of clinical outcomes. Data and network analyses were performed using IBM SPSS Statistics, SAS v 9.4, and STRING V11.

Results Increased systemic $(\mathrm{p}<0.001)$ and intracranial $(p=0.013)$ levels of VCAM1 were associated with the presence of hypertension. Intracranial VCAM1 was positively correlated to both infarct volume $(\mathrm{p}=0.032 ; \mathrm{r}=0.34)$ and edema volume $(p=0.026 ; r=0.35)$. The $\% \Delta$ in NIHSS from admittance to discharge was found to be significantly correlated to both systemic $(\mathrm{p}=0.013 ; \mathrm{r}=-0.409)$ and intracranial $(\mathrm{p}=0.011 ; \mathrm{r}=-0.421)$ VCAM1 levels indicating elevated levels of systemic and intracranial VCAM1 are associated with reduced improvement of stroke severity based on NIHSS from admittance to discharge. STRING-generated analyses identified biologic functional descriptions as well as function-associated proteins from the predictive models of infarct and edema volume.

Conclusions The current study provides novel data on systemic and intracranial VCAM1 in relation to stroke comorbidities, stroke severity, functional outcomes, as well as the role VCAM1 plays in complex protein-protein signaling pathways. These data will allow future studies to develop predictive biomarkers and proteomic targets for drug development to improve our ability to treat a devastating pathology.

Disclosures B. Maglinger: None. M. Sands: None. J. Frank: None. C. McLouth: None. A. Trout: None. J. Roberts: None. S. Grupke: None. J. Turchan-Cholewo: None. A. Stowe: None. J. Fraser: None. K. Pennypacker: None. 